\title{
12. LEARNING AND TEACHING SCIENCE WITH ANALOGIES AND METAPHORS
}

INTRODUCTION

Analogies and metaphors have always been important in learning and teaching science. Indeed, science teachers who communicate ideas and concepts in their classrooms using analogies are in good company. Many important discoveries in science have been made in this manner. For example, Johannes Kepler developed science have been made in this manner. For example, Johannes Kepler developed
his concepts of planetary motion from the workings of a clock, Christian Huygens his concepts of planetary motion from the workings of a clock, Christian Huygens
used water wave motion to understand light phenomena, and Kekule developed the used water wave motion to understand light phenomena, and Kekule developed the
idea of the benzene ring from his dream about a serpent biting its own tail. Yet, analogies and metaphors only became a significant field of Australasian science education research in the late 1980s, with most research papers appearing in international journals from the early 1990s. Since this time, science education researchers in Australia and New Zealand have made significant contributions to research on learning and teaching science with analogies and metaphors.

In this chapter, we review Australasian research to outline the broad pathways this research has followed and to highlight significant contributions the work has made to science education. We describe a series of studies from different research groups and highlight two seminal publications that are discussed later in finer detail. The first publication Metaphor and analogy in science education (Aubusson, Harrison \& Ritchie, 2006a) provides a state of the art analysis of how metaphors and analogies are used in science classrooms; the majority of the authors are Australasian. The second publication Using analogies in middle and secondary science classrooms (Harrison \& Coll, 2008) provides both a scholarly argument for using analogies in science teaching and also presents 50 concepts from biology, chemistry, physics and earth and space science that have been taught using a model chedel or effective analogy teaching. where gaps remain in our understanding of the role of analogy and metaphor in cience education and suggests emerging fields for further study.

In his review of the role of analogies and metaphors in learning science, which began during a period of sabbatical leave at Curtin University, Duit (1991) noted that analogies allow new material, especially abstract concepts, to be more easily assimilated with students' prior knowledge, enabling them to develop a more scientific understanding of the concept. A key question for science education researchers and science teachers to investigate has been whether students can economically and repeatedly employ these same analogical reasoning skills to

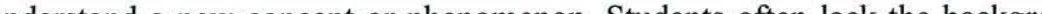


learn difficult and unfamiliar concepts in biology, chemistry, and physics, so one effective way to deal with this problem is for the teacher to provide an analogical bridge between the unfamiliar concept and the knowledge which students possess. For example, biology teachers often explain the specific way that enzymes interact with substances by using an analogy with a lock and key; physics teachers might explain the forces acting when a book rests on a table by using an analogy with an object on a spring; chemistry teachers might explain chemical bonds in terms of friendship bonds.

The Meaning of Analogy

Before moving further we pause to clarify what we mean by analogy in the context of the science education research being reported in this chapter. The usage of the term analogy in science education has been varied and in many cases the terms metaphor, analogy and model have been used interchangeably (Aubusson, Harrison \& Ritchie, 2006b). An analogy is a process of identifying similarities between two concepts. The familiar concept is called the analog and the unfamiliar science concept is called the target. When using an analogy in science teaching, ideally teachers should select an appropriate student world analog to assist in explaining the science concept. The analog and target share attributes that allow a relationship to be identified and contribute to the concept being taught; however, here canse impaired learning if incorrectly matched. Many authors provide examples of this; one such example - the camera as the base analog and the eye as the target adapted from Harrison (2006) - is used to illustrate this mapping shown in Figure 1. In this example of the camera and the eye analogy, there are features of the eye and camera, which are similar while others are different.

Analogies are believed to help student learning by providing visualisation of abstract concepts, by helping compare similarities of the students' real world with new concepts, and by increasing students' motivation (see Treagust, Harrison, Venville \& Dagher 1996). Concrete analogs facilitate understanding of the abstract concept by pointing to the similarities between objects or events in the students world and the phenomenon under discussion. Analogies can be motivational in that, as the teacher uses ideas from the students' real world experience, a sense of intrinsic interest can potentially be generated. From a teaching perspective, the use of analogies can enhance conceptual change learning since they open new perspectives (Venville \& Treagust, 1996)

Despite their advantages and usefulness, analogies also can cause incorrect or impaired learning depending on the analog-target relationship. If the teacher uses an analog that is unfamiliar to the learner, development of understanding through the analogy is prevented. However, the use of analogies in science teaching does not always produce the intended effects, especially when students take an analogy too far and are too far and are une stucents only renemer focus upon extraneous aspects of the analogy and draw spurious conclusions about the target concept. There are also possible problems with using analogies from a developmental perspective and research has shown that analogies are more usefu for concrete operational thinkers.

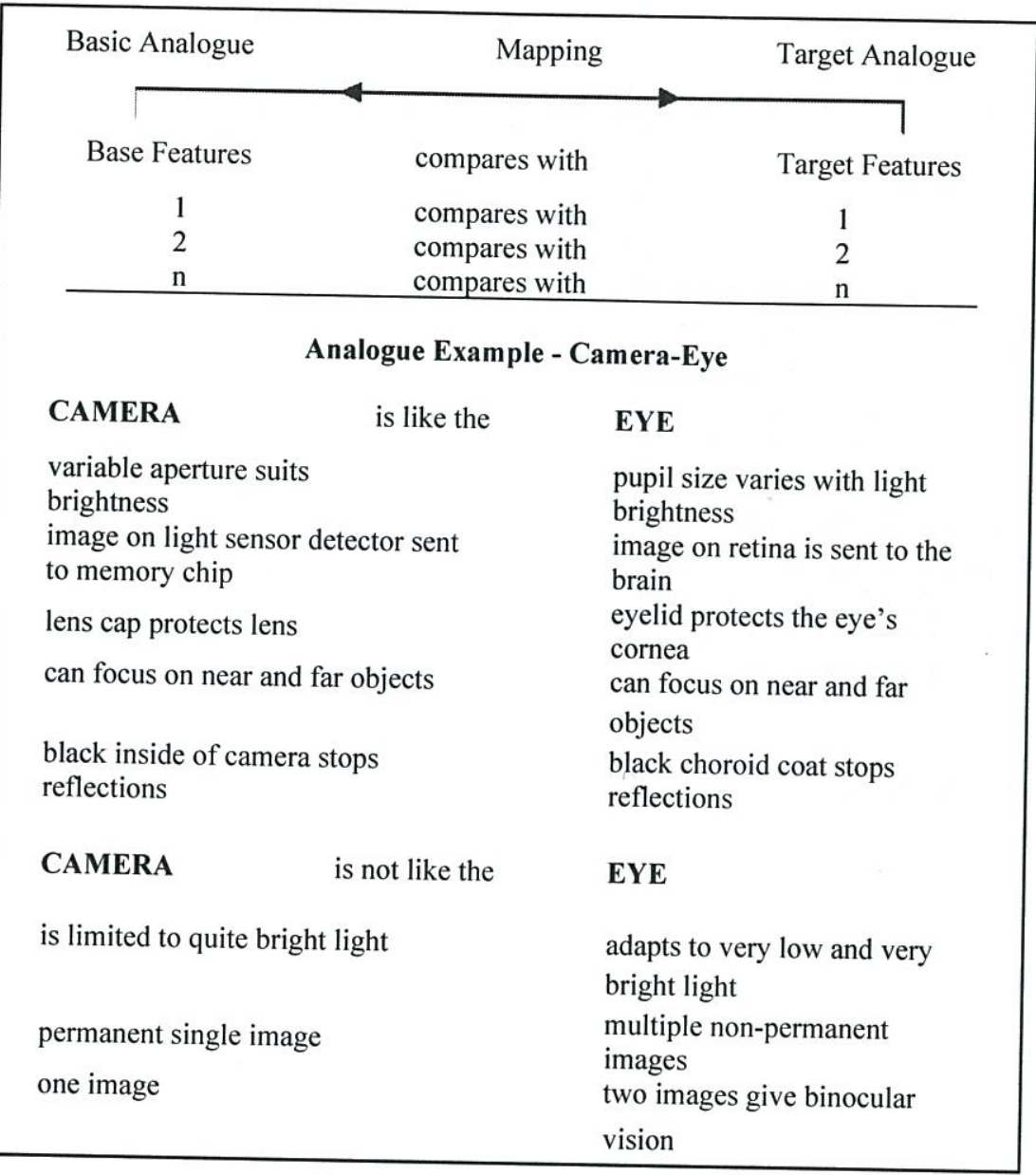

Figure 1. Analogical Mapping

Two Pathways for Researching about Analogies and Metaphors

Viewed in retrospect, the desire to understand analogy in the learning and teaching of science was in part an outcome of a renewed respect, which had momentum during the second half of the last century, for the role of metaphor and analogy in knowledge exchange and production as well as their influp and people's perceptions of their world (Aubusson, et al 2006b). At the time, however, the ontology and epistemology of this research had its foundat the however, 
children's science and conceptual change that dominated science education in the 1970 s and 1980s. This body of knowledge led a group of researchers at Curti University to ask, "How are teachers making concepts accessible and comprehensible to students?" One potential tool for such a purpose seemed to be analogy but, at the time, little was known about the extent of use of analogy or the pedagogies associated with their use in science classes. Indeed the work of Treagust, Duit, Joslin an Windauer (1992) was one of the first publications to examine how analogies are Lindau (1992) we previous research was published used in the natural classroom setting; much of the previous research was published in psychology journals reflecting the analytical examination of indiones
performance of analogical thinking in psychology laboratory experiments.

performance of analogical thinking in psychology laboratory experiments.

These early studies instigated two broad pathways of investigation. The first and most prolific grew from Treagust's and later Harrison's work, described in more detail later, led to many investigations exploring and improving the ways in which analogies were selected, designed and employed in science teaching and learning. This research consisted of a series of ongoing, related threads of research: observing teachers in science classes to see how they used analogies; investigations of textbook analogical representations of science concepts; studies of the way of textsolopment of a model for teaching using scientists
analogies.

Other researchers such as Cosgrove (1995), Aubusson, Fogwill, Barr and Perkovic (1997), and Fogwill (1995), independently, identified the significance of Perkovic (1997), and Fogwill (1995), independenty, ident analogy in teaching and learning science and followed the Curtin pioneers with their own studies of analogy in science learning. A number of these studies were distinctive from the Curtin research in that their focus was on student-student or student-teacher co-generated analogies rather than textbook or teacher-generated analogies.

The second pathway examined the way in which science teacher metaphors explained and influenced the ways that teachers perceived themselves as teachers and how analo could be used to influence teaching change. This pathway was influow influenced by questions such as, Can mera change the way they see themselves as teachers and thereby change the ways they teach science? This work, initiated by Tobin (1990), was in the USA (e.g., Tobin, 1993; 1996; Tobin \& Tippins, 1996) and Australia (e.g., Aubusson \& Webb, 1991; Ritchie \& Russell, 1991; Ritchie 1994)

Thomas and McRobbie (1999a; 1999b; 2001) applied similar principles to thei studies of the potential of metaphor to inform students' metacognition and to influence students' understanding of their learning in school science classes. Analogical theory has also been adapted as a procedure for analysis in science education research and applied to developing understanding of science education education research and applied to developing understang of the scope of this chapter.
THE FIRST PATHWAY: LAYING THE FOUNDATIONS OF ANALOGIES INFORMING SCIENCE TEACHING AND LEARNING

How Teachers use Analogy

The seminal study of 50 science lessons investigating how teachers taught science (Treagust et al, 1992) indicated that analogies were under-utilised and poorly used in science classes. This study was followed by a series of investigations of analogy use in science teaching by Treagust and his doctoral students, first scrutinising current practice and then using intervention studies to determine ways of making current practice and then using intervention studies to determine ways of making
teaching with analogy more effective. An important finding of this work was that teaching with analogy more effective. An important finding of this work was that
analogies require explanation and analysis if they are to contribute to appropriate analogies require explanation and analysis if they are to contribute to appropriate
conceptual change. These studies resulted in the development of a model for conceptual change. These studies resulted in the development of a model for
teaching using analogies called the FAR guide (see details later in the chapter). teaching using analogies called the FAR guide (see details later in the chapter).

A consistent finding in studies of analogy has been that they are "two edged swords" (Harrison \& Treagust, 2006), being both able to lead students in their development of sound scientific conceptions as well as able to mislead student resulting in the construction of alternative conceptions. Thus much of the research has concentrated on the use analogies to promote the former and inhibit the latter. These studies indicated that in the hands of a skilled teacher analogies had great potential to contribute to student understanding of science concepts and phenomena. The case has been consistently made, however, that effective teaching with analogies requires the teacher to assist students to map the features of the base analog against the science concept, proposition or phenomena under study. The wheel-refraction analogy (Harrison \& Treagust, 1993) provides an illustration of such a mapping. In this analogy, for example, the wheels with axle behave like the light ray traveling across different surfaces (air - paper, glass - carpet) where, like light, the wheels travel at different speeds as they traverse (go-through) different media-surfaces. When the teacher works with students to make explicit the mismatches between the analog and the target (see for example the mapping of similarities and differences eye camera analogy in figure 2), students are less likely How Texts use Analogies

Following the research by Treagust et al. (1992), a series of studies was conducted by the Curtin group, supported by Australian Research Council large grants, that investigated analogies in senior high school textbooks of chemistry (Thiele \& Treagust, 1993, 1994b, 1995), of physics (Stocklmayer \& Treagust, 1994) and of biology (Thiele, Venville \& Treagust, 1995). These studies, which used a classification of analogies proposed by Curtis and Reigeluth (1984), indicated that while cation of analogies proposed by Curtis and Reigeluth (1984), indicated that while
many textbooks frequently used simple analogies few textbooks stated any limitations many textbooks frequently used simple analogies few textbooks stated any limitations
of the analogies; consequently, these simple analogies were likely to create learning problems for students. In some textbooks authors made use of margin spaces to include analogies that often contained a pictorial component. The article by 
Stocklmayer and Treagust (1994) looked specifically at the way that textbooks, over a period of one hundred years, used analogies to inform readers about electric current.

\section{A RAY OF LIGHT BEING REFRACTED AS IT PASSES}

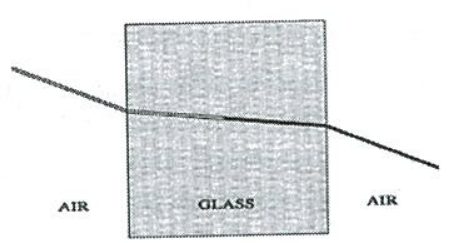

IS LIKE

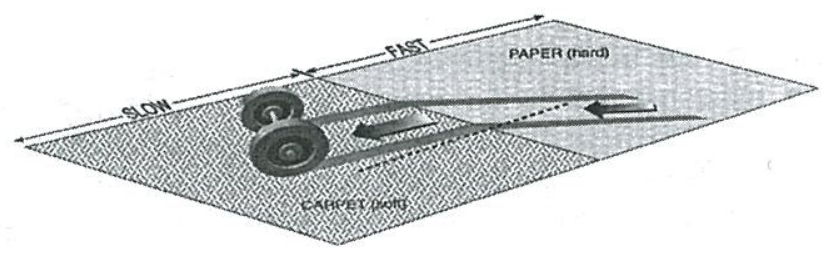

Figure 2. The wheels-refraction of light analogy

A Guide for using Analogies

In general terms, all researchers agree that the mapping of like and unlike attributes is essential to any effective pedagogy using analogy for science learning. The extensive body of research produced a guide for teaching with analogies (Treagust, Harrison \& Venville, 1998) called the Focus - Action - Reflection (FAR) Guide (see figure 3) that has been shown to enhance learning of science conceptions and (see fire reduce the constricted in our research helped develop competent and interest the

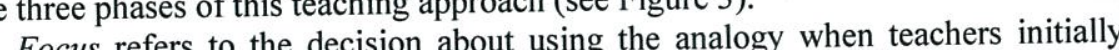
Focus refers to the decision about using the analogy when fifficulties for the consider the difficult aspects of the concept to be taught (i.e., difficulties for the teacher and the students), whether or not the students already know something about the target concept, and whether or not the students are familiar with the analog.

\begin{tabular}{|c|c|}
\hline \multicolumn{2}{|l|}{ Focus } \\
\hline Concept & Is it difficult, unfamiliar, or abstract? \\
\hline Students & $\begin{array}{l}\text { What ideas do the students already know about the } \\
\text { concept? }\end{array}$ \\
\hline Analog & Is it something your students are familiar with? \\
\hline \multicolumn{2}{|r|}{ 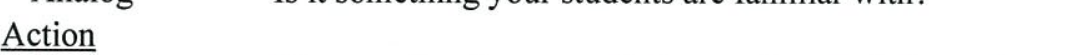 } \\
\hline Likes & $\begin{array}{l}\text { Discuss the features of the analog and the science } \\
\text { concept. Draw similarities between them. }\end{array}$ \\
\hline Unlikes & $\begin{array}{l}\text { Discuss where the analog is unlike the science } \\
\text { concept. }\end{array}$ \\
\hline \multicolumn{2}{|l|}{ Reflection } \\
\hline Conclusions & Was the analogy clear and useful or confusing? \\
\hline Improvements & Refocus as above in light of outcomes. \\
\hline
\end{tabular}

Figure 3. The FAR Guide for Teaching and Learning with Analogies.

Action refers to the class presentation when the teacher pays careful attention to the students' familiarity with the analog and identifies the Like attributes (i.e., those features in common) and the Unlike attributes (i.e., those features not in common) of the analog and the target. To achieve this, the features of the analog and target are socially negotiated with students, similarities are drawn between them, and ways that the analog and target are not alike are explicitly identified. them, and ways that the analog and target are not alike are explicitly identified.
The Action phase of analogical teaching usually involves no more than three The Action phase of analogical teaching usually involves no more than three
cognitive steps: (a) familiarity with the analog, (b) mapping of the shared cognitive steps: (a) familiarity with the analog, (b) mapping of the shared
attributes, and (c) negotiating with the students where the analogy breaks down.

Reflection takes place after the analogy has been used in class when the teacher reflects on the clarity and usefulness of, and conclusions drawn from, the analog and considers ways in which the analog, the mappings, or the analogy's position in the lesson may be improved. This Reflection phase may take place within the lesson itself or after the lesson as later preparation occurs. In practice, these phases cteristic of all good teaching, competent teachers will likely implement this step as a matter of course.

The purpose of the FAR Guide is to help teachers maximise the benefits and minimise the constraints of analogies when they arise in classroom discourse or in textbooks. The guide came about as a result of many hours observing and interviewing teachers and students and has been designed, as much as possible, to reflect the skilled way in which exemplary, experienced teachers use analogies to teach science. Because the three phases-Focus, Action, Reflection-are quite self-explanatory and epitomise good teaching, most teachers assimilate the FAR Guide with ease and their students benefit from and enjoy anasies when teaching Guide with easen teaching (2000) aso investigated how expert studientist used analogies.

Studies with a group of interested teachers in their classrooms commenced parallel with the textbook research. These studies initially followed the Treagust 
et al. (1992) ethnographic approach identifying how teachers used their own analogies effectively in chemistry (Thiele \& Treagust, 1994b) and in physics analogies effectively in chem). Other articles, initiated by Harrison based on hi (Harrison \& Treagust, 1993). Other articles, inited ways that analogies could be experience as a long-time science teacher, described (Harrison \& Treagust, 1994a) used effectively, for example, to teach \& Treagust, 1994b).

and the three states of matter (Harrison \& Treasust,

Initially, these analogy studies by the Curtin group had no teaching intervention. This changed in Harrison and Treagust (193) when the teacher used a modified version of Glynn's Teaching-With-Analogies (TWA) model with grade-10 optics class on refraction. This study was important in that it led the research team to develop an approach called the FAR Guide (Focus-ActionReflection) (1991) for teaching science with analogies (Treagust, Harrison, \& Venville, 1998). Other research involved teachers improving students' understanding Venville, 1998). Onus using elaborated analogies (Venville, Bryer \& Treagust (1994). of scientific Treagust (2001) prose classes with studies involved the teach aced on grade 9 students one exception- he work of Con creating their own analogies to explain scientic phen curriculum using a is discussed later, the studies by Aubusson and his colleagues had a focus student-generated analogies that arose independently of the Curtin researchers.

Implementing this teaching approach led to perhaps the most influential of the analogy studies of the Curtin group as the researchers examined the role of analogies in engendering conceptual change in optics (Treagust, Harrison, Venville \& Dagher 1996) and in a range of biology topics, the latter from four different \& Dagher, 1996) and in a

Model-based Learning in Science

The rese of models The research on analogies in science led naturall (1999) (see also Coll \& Treagust, in science. An innovative investigation by Coll (1999) (see almistry learners sought 2002a) involving secondary, undergraduate and graduate chemistry learl \& Treagust to determine their preferred mental models of covalent bonding (Coll \& T Coll \& 2002b), ionic bonding (Coll \& Treagust, 2003a), and metallic bonding (Coll \& Treagust, 2003b), by means of semi-structured interviews with a variety of focus cards depicting models of bonding. The study revealed that, despite having expertise in a number of highly complex and mathematically sophisticated mental models, tertiary students, including graduate students, showed a strong preference for simple realistic mental models and at the same time retained alternative conceptions.

In a study that investigated secondary students use of models in organic chemistry, Treagust, Chittleborough and Mamiala (2004) found that the majority of students had a sound understanding of the descriptive nature of analogica models but their understanding of the predictive nature of models was limited despite the experience of using a variety of representations in chemistry class. The study suggested that teaching models play a pivotal role in initiating students' development of scientific models, mental models and expressed models. Late studies incorporated a wide variety of pencil-and-paper tasks designed and administered to measure secondary students' understanding of scientific models (Treagust, Chittleborough \& Mamiala, (2002) and secondary and university students' perceptions of the role of models in science as well as in learning science (Chittleborough, Treagust, Mamiala \& Mocerino, 2005). Mostly students' responses revealed a developing understanding; scientific models were associated with the process of science and teaching models were related to the process of learning science.

Co-generated Analogies

In the above studies of teaching with analogies, the way in which teachers interacted with students to create analogies was observed and reported. Treagus et al. (1996) noted that students were capable of developing rich analogies to explain refraction. Furthermore, Harrison and de Jong (2004) observed that learning of science concepts was sometimes enabled when students responded to a teacher's alo whe a to chemical equilibrium a student responded with an analogy of a boiling saucepan sealed with a lid, where the rate of evaporation equals the rate of condensation. This observation illustrates the way in which analogy can provide an exchange of views where both teacher and student select and present analogies that carry meaning for them.

Other researchers focused specifically on teacher-student co-generated analogies. Among his series of studies of students' understanding of electric current, Cosgrove (1995) investigated the merits of working with primary school students to assist them to construct their own analogy of electric current. With him, they developed a role play where the students took on the part of electrons and moved around a circle as energy carriers. They collected energy from a battery and released energy in an energy transformation at a light bulb. Their movements and the amount of in an energy transformation at a light bulb. Their movements and the
energy carried were influenced by a variety of changes to the circuit.

energy carried were influenced by a variety of changes to the circuit.
At about the same time, Aubusson et al. (1997) collaborated in investigating At about the same time, Aubusson et al. (1997) collaborated in investigating
ree case studies of learning science through analogies. The three teachers assisted students in developing their analogies to explain what they thought were occurring when a current flowed through simple circuits or when gasses were exchanged in human blood circulation. These studies identified that co-generated analogies could make a significant contribution to student learning when the analogical developmen was carefully moderated by the teacher. In particular, the teachers needed to the the to encouresentations an carefully map analogical attibutes. Notably, in one of the cases where students were dealing with concepts and phenomena that they found very difficult to
understand, this process required many lessons. 
In Fogwill's class, the development of the analogies progressed through iterations or mactical werk and text-bod sources. In all these studies one of the aims in the construction work and text-based sossible, of the analogy was to develop an analogical model the wisce that is, an analogy where many important, causal relationships could be mapped
between the target and base analogs.

More recent studies of co-generated analogies (Aubusson \& Fogwill, 2006; Fogwill, 2007) have suggested that the development of an analogy that represents the phenomenon as accurately as possible may be an unnecessary or inappropriate goal. In particular, these authors noted that even poor analogies, in the sense that they may not represent the phenomenon accurately, could be valuable in learning if the teacher required students to explain and discuss the analogies in depth to identify the reasons why the analogy does and does not accurately represent their identify the analogy may view of the pheme not be the most important aspect, rather the quil, 2006). These authors' discussion is critical (Aubusson \& Fogwill, 2006). These authors current speculation is that it is not just that thoroughly explaining the mismatch between a target and base analog demonstrates a very sound understanding of the target phenomenon, rather that the creation and analysis of the matches and mismatches enables students to generate a more sound understanding of the phenomenon and related science concepts.

When teachers engage students in discussion with the analogies that students construct, the students are more readily able to map attributes of their analogies than those provided by the teacher (Harrison \& de Jong, 2005; Harrison, 2006). In this way, the usefulness of co-generated analogies becomes evident because when this way, the usefulas students develop the analogies the learning based on their own experiences (Aubusson \& Fogwill, 2006). When students create their own analogy they use things with which they are familiar to represent their view of the phenomenon at the time. Subjecting the analogy to scrutiny by making decisions about how well the analogy conforms to practica evidence or information available to the students allows them to discuss its strength and weaknesses, and thereby clarify their personal theories. The students may refine and improve the analogy. On the other hand, the analogy might be judged inadequate and set aside once it has done its work in promoting the discussion an inadequate and substien \& Fogwill, 2006; Fogwill, 2007). The end to keep in mind, when using analogy for learning, is 2006, Fogwill, 2007). The end not the perfection of an analogy per se but the lom process of interpreting, explaining and discussing the analogy. This later point is the essential focus of the work of Bellocchi (2008) who, in using analogy-writin activities in his Year 11 chemistry class, noted that the students' discussion of the analogies involved their own hybridization of the elements of both the analog an target discourses.
Analogy and the Affective Domain

It seems surprising that while the relationship between student interest in and attitude towards science have often been informally discussed among researchers in the field at conferences and in personal communications, little research has targeted this aspect of analogy in school science. Nevertheless, the little data we have are encouraging. Fogwill (1995) and Aubusson and Fogwill (2006) reported that students like lessons in which analogies were used to learn science. Harrison reviewed over 15 years of his research of analogies and foumd many examps cuppoted the hyp supported the hypothesis that teaching with analogies could contribute to student interest and enjoyment of science (Harrison \& de Jong, 2004; Harrison, 2006). He also noted that many of the teachers exhibited enthusiasm and were animated when using analogies in their teaching. In preparing this chapter, when reading many of the quotations cited by researchers to indicate learning or thinking processes among students, it seemed that the quotes often implied that students were interested and engaged in their conversations using analogies-both when it occurred in class and during research interviews.

An excellent example of how analogies engender interest and motivation in science conceptualisation is the interview with a student named Dana in the optics lessons reported by Treagust et al. (1996) and described in more detail in Hapison (2006). Essentially, Dan's et al (1996) and described in more deail in Harison (2006). Essentics lessons we rom disinterested to enthusiastic and knowledgeable once the analogy was evoked. Thus, while the evidence is scant, there appears to be a prima facie case to investigate the relationship between learning and teaching with analogies and students' interest and enthusiasm for science.

THE SECOND PATHWAY - LAYING THE FOUNDATIONS FOR RESEARCH ON METAPHORS OF TEACHING SCIENCE

At about the same time that Treagust and his colleagues began to investigate teachers' use of analogy in science lessons, other studies such as those by Tobin, Kahle and Fraser (1990) raised questions about how and why science teachers taught as they did. Tobin (1990) provided an analogical interpretation of the science teaching-learning nexus; a key finding of this research on metaphors science teaching-learning nexus; a key finding of this research on metaphors
revealed that how teachers see themselves as teachers may not match how they revealed that how teachers see themselves as teac
might want their students to operate as learners.

This is a path less well trodden. In 1990, Tobin invited the science education community to consider the potential of metaphor as a "master switch" for teachers changing their view of themselves as teachers, their students and, thereby, the ways they teach. In this and a later study (Tobin, 1990; 1996; Tobin \& Tippins, 1996) was argued first that science teachers' strongly held beliefs about their role as teacher could inhibit the development of more innovative teaching practice; and second that by enabling science teach to re-vision ther modifying the metapho (s) that gy modifying the metaphor(s) that guide their teaching, they could make changes to their teaching that were desirable to them. Tobin (1990) provides the case study of Sarah illustrating this aspect: 
Important beliefs that applied ... were described in terms of a distance metaphor... Sarah explained she should be distant from the students. Yet as a facilitator of learning Sarah believed she should be close to students. These metaphors seemed to imply a contradictory course of action... Sarah had problems, (and) wanted to make changes ... She decided to reconceptualize her role as manager in terms of being a social director... According to the her role as manager in terms of being a socitunities for learning and invite metaphor, the teacher's role is to create opportunities forah pursued her (new) students to learn, as guests are invited to a part... Sand student behaviour (pp. 124-125)

In particular, it seemed evident that if a teacher viewed him or herself as, for In particular it ifficult to move example, captain of a towards student-centred approach teacher expressed a desire to do so. Howning and learning change becomes more compatible with a desired mode of teaching and learning change becomes more likely.

The invitation to encourage teachers to review and change their beliefs about themselves as teachers and how they go about teaching was taken up by a number of researchers including Aubusson, Ritichie and others (Aubusson, 2006; Aubusson \& Webb, 1991; Ritchie \& Russell, 1991; Ritchie, 1994; Ritchie, Bellocchi, Poltl \& Wearmouth, 2006; Thomas and McRobbie 2001)

When working with primary school science teachers, Aubusson and Webb Wi1 (1991) asked a themselves a professional development teacher as teachers using a metaphor. Most described metaphors that en asked to identify what organiser and controller. A few days later they we then asked to identify what role the teaching metaphor indicated for their students. For example, the teacheras-musician suggested a role for students as piano keys she played. Once they had logically derived their metaphor for learners from their metaphor for teacher, many teachers were very dissatisfied with the role they assigned their students. Typically they sought to review and change their teaching metaphor. As one teacher reflecte the coach who can leave the game to the players once it is in progress and wait until half time to be able to have more the players on court during the game" (p. 26)

game" (p. 26). Ritchio (Ritchie \& Russell, 1991; Ritchie, 1994) worket com teacher-centred to teacher Bernice who sought to change the way she tught for student-centred. She developed a rich analogy of science teacher-as-travel agent for herself. According to her view of the teacher as travel agent: The teacher-astravel-agent could arrange for different students to learn different things in different ways - travel to different destinations by different means, organize travellearning for small or large groups etc. However, the student as traveler also had to take significant responsibilities as traveler. By using the teacher-as-travel-agen metaphor to guide her decisions and action as teacher, Bernice revolutionized her medar students learnt science in her classes. These early studies involved teachers seeking change and working through metaphor with support from a researcher. Recent studies have also indicated that teacher metaphors can be used collaboratively to stimulate discussions and analyi rentys that provide rich insigh (An teaching and earning in science (Aubusson, 2006, Ritchie, et al., 2006). These studies of teacher metaphors as a master switch for change indicate that analogy can provide a tool to: create teacher dissatisfaction with the status quo as a precursor to change; clarify what a teacher would like to become; and facilitate change towards a desired student-centred teaching. The last of these, however, has only been reported on a small scale with one or a few teachers with considerable support from a researcher.

The Science Learner

Influenced by notions of metacognition, Tobin's (1990) work was taken in a different direction by Thomas and McRobbie (Thomas, 1999; Thomas \& McRobbie, $2001 ; 2006)$ who asked, if metaphor can be used to influence teacher beliefs and teacher change, might they not also be useful in encouraging students to change the way they see themselves as learners. Thomas and McRobbie first established that students could meaningfully describe and communicate ideas about how they saw themselves as learners in terms of metaphors. Later they worked with science students asking them to use metaphors to outline their beliefs about learning in science (Thomas \& McRobbie, 1999, 2001). Students were encouraged to describe atributes of their metaphors in a detailed mapping. Similarly, the teacher (Thomibe (Thomas) made explicit to his stuents in teaching. Consequently, some students reinterpreted or modified their learner metaphors and changed their learning behaviour. Changes included strengthening features of their learning strategies to better match features of constructivist and connecting metaphors that they perceived to be important for their learning. Tim, a science student, explained:

The metaphor's the principle of the way I learn. I just go on with what the metaphor's taught me. I just think about what we"ve done in the past, which is what the metaphor's really saying... when I see something new I find out where it fits in with what I"ve learnt in the past. Way back ago we had a test and we were talking about buckyballs, and I was reading about a week ago that they"ve now got 120 carbon atoms or something like that; like the next step up from buckyballs. Before we"d done the metaphor I would never have considered those sorts of connections. In the past I just read though [the text] and hope to learn it off by heart. I still read the text .. but now when I read, I and hope to le " it fit?" and I can tell myself "This has to do with that". (Thomas, 2006)

As in the studies of teacher change, it is noteworthy that science students' views of themselves as learners and the way they went about learning could change. Yet, the 
changes required considerable support from an expert science teacher familiar with metaphor, research and constructivist learning theory.

In all the cases reviewed where change was reported in patterns of teaching and learning, the metaphor was not used in isolation. Significantly, the metaphors were allied with discussions about constructivist notions of learning and/or teaching approaches consistent with such a referent. Thus the metaphor did not act independently but as a bridge from familiar ways of learning and teaching to understanding and enacting new constructivist ways of learning and teaching. The undertand metaphors provided a reasoning tool to map matches

WHITHER ANALOGY AND METAPHOR IN SCIENCE EDUCATION?

Much has been achieved in Australasian studies of analogies and metaphors in science education providing a foundation for further research. However, there is a need to rethink what is meant by "familiar". There is universal agreement among researchers that one reason for the effectiveness of teaching with analogies is that the familiar is used to make the unfamiliar accessible and understandable. Yet, it is debatable how familiar some analogies are. For example, using the analogy of two whecls on an a provide an analog for refraction (Harrison \& Treagust, 1993) has proved productive but it is difficult to sustain an argument that students are very familiar with the movement of such wheels across different surfaces. The same could be said of many of the analogies reported above. On the other hand, if the pairing up of electrons is compared to students at a party pairing up to dance, it likely that students are familiar with the couple dancing but that the mapping between the base and target analogs is limited. An important difference in these instances (and many analogies) is that in some analogies, the base analog already exists as a complete entity while others need to be constructed, and put together from a number of parts. In the camera eye analog, for example, the camera provides an existing available analog base eye an. mapping. By contrast, many analogies rovire varying degrees of constion. A truck (electron) carrying a (ency) load around a circular track as an analogy for electric current requires little adaptation. However the analogies of students moving in a circular path carrying balloons with the addition of a suite of analog to model the battery, ammeters, voltmeters, batteries etc. (e.g., Aubusson, et al. 1997; Cosgrove, 1995) require considerable modification from familiar experience.

Thus there exist vast differences in analogy in terms of their degree of construction and the extent of their familiarity. Even when students construct the analogies themselves, they typically use familiar objects but it is difficulty to argue that the analog they produce is familiar or pre-existing. Take for example the the constructed their analogy using their own movements and books to produce complex simulation role play including covalent bonds, ionic bonds, an (Aubusson \& Fogwill, 2006). We need research to understand the ways in which analogies are constructed to explore, for example, differences in the ways in which pre-existing familiar things (e.g., camera-eye) and constructed analogs (e.g., electric current role play simulations) influence learning. The task remains to determin where co-construction and where pre-existing analogies can be used most effectively in science lessons.

Long since Tobin first proposed metaphor as the master switch for change, the findings of small-scale interventions with willing teachers are promising. The capacity of metaphor guided reflection, among larger groups of teachers, has capacity of metaphor guided reflection, among larger groups of teachers, has shown its capacity to promote dissatisfaction with current views of teaching and to suggest alternatives when linked to existing explicit alternative ways of teaching (e.g., contructivist-related approaches). However, it is by no means certain that the use of metaphor to improve science education provides a viable, educationally significant change strategy. There is a need to examine whether the intensive intervention by researchers can be reduced and whether collaborative teams of teachers might make it possible for large scale change effects to be realized.

Little is known about the relationship between the use of analogy in science teaching and the positive, affective outcomes some researchers have science Furthermore, the long-term influences on science learning and memory of using analogies in teaching concepts is almost unexamined. We know little about how students continue to draw on analogies used in science classes when they go about their daily life or in science assessments, such as responding to examination questions. Treagust and Harrison (1993) reported on student understanding of refraction some weeks after learning about it through analogies and noted that the wheel and axle analogy continued to influence students understanding.

Also, Fogwill (2007) observed that many months after lessons, students recalled analogies from their science classes. Some students themselves moving arms as they had done during role-plays, when anwined questions in the final end of school physics examination. However, such researing is rare In particular, it would be fuifful to rexm to their learning experiences with an anal to return to students months or a year after their learning experiences with an analogy to investigate: the extent to which their conceptions have developed, reverted or further shaped by the analogy; when, if and why the students continue to call upon analogy; and the ways in which the analogy does or does not influence their recall of knowledge.

Much research has been conducted to investigate the ways in which teachers work with students using analogical mapping strategies to promote effective use of analogy to generate clear "accurate" understandings. However, we know of research that has investigated whether such productive learning processes are transferred to other settings or implemented by students themselves whes the think with analogies in the absence of a teacher. After 25 years, sties analogies and metaphors in science education have taken us a lows, studies of enriching ourds enriching our philosophical, theoretical and practical knowledge. Nevertheless,
much remains to be learnt. 
REFERENCES

Aubusson, P. (2002). An ecology of science education. International Journal of Science Education, 24,

27-46.
Aubusson, P. J. (2006). Columbus and Crew: Making analogical reflection public. In P. J. Aubusson \& S Schuck (Eds.), Teacher learning and development: The mirror maze (pp. 91-106) Dordrecht: Springer.

abusson, P. J., Harrison, A. G., \& Ritchie, S. M. (2006a). Metaphor and analogy in science education. Dordrecht: Springer.

Aubusson, P. J., Harrison, A. G., \& Ritchie, S. M. (2006b). Metaphor and analogy: serious thought in science education. In P. J. Aubusson, A. G. Harriso

in science education (pp. 1-9). Dordrecht: Springer.

Aubusson, P. J., \& Fogwill, S. (2006). Roletaphor and analogy in science education (pp. 91-102). Dordrecht: Springer.

Dordrecht. Springer. . (1991). Teacher beliefs about learning and teaching in primary science and technology. Research in Science Education, 21, 10-19.

Aubusson, P. Barr R. Perkovic, L., \& Fogwill, S. (1997). What happens when students do simulationrole-play in science. Research in Science Education, 27, 565-579.

Bellocchi. A. (2008, July). Merged discourse - hybrid language developed by students during analogywriting activities in a chemistry class. Paper presented at the annual meeting of the Australasian Science Education Research Association, Brisbane.

Chittleborough, G., Treagust, D. F., Mamiala, T.L., \& Mocerino, M. (2005). Students' perceptions of

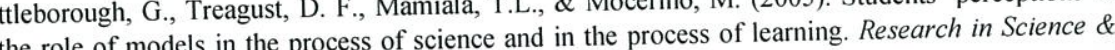
Technological Education, 23, 195-212.

Coll. R. K. (1999). Learners' mental models of chemical bonding. Unpublished Doctoral Thesis, Curtin University of Technology, Perth, Australia.

Coll, R. \& Treast, D. F. (20032). Investigation of secondary school, undergraduate and graduate . Cross-age study. Coll, R., \& Treagust, D. F. (2003b). Learners' mental Rodes of 's Science Educalion, $87,685-707$.

Coll, R., \& Treagust, D. F. (2002a). Learners' use of analogy and alternative co

bonding: A cross age study. Australian Science Teachers Jounal, $48,24-32$. Coll, R. K., \& Treagus, $1,357-382$.

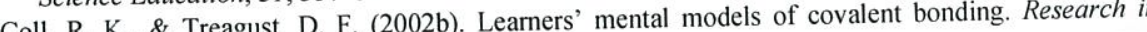
Coll, R. K., \& Treagus, and Technological Education, 20, 241-268.

Cosgrove, M. (1995). A case study of science-in-the-making as students generate an analogy for electricity. International Journal of Science Education, 17, 295-310.

Crowley J. (2002). Analogies constructed by students in a selective high school. Unpublished Doctora Crowley, J. (2002). Analogies co Technology, Perth, Western Australi

Thesis. Curtin University of Technos). The use of analogies in written text. Instructional Science, 13 Curtis, R. V.

On the role of analogies and metaphors in learning science. Science Education, 75 , 649-672.

649-672. Fogwill, S., $(1995$

Fogwill, S. (2007, July). Year 11 Physics students generating analogies to develop and show understanding - is this quality teaching and learning? Paper presented at the annual conference the Australasian Science

Glynn, S. M. (1991). Explaining science concepls. A teaching-with-analogies model. In S. Glynn, R. (19-240). Hillsdale, NJ: Erlbaum.
Harrison, A. G. (2006). The affective dimension of analogy. In P. J. Aubusson, A. G. Harrison, \& S. M. Ritchie (Eds.), Metaphor and analogy in science education (pp. 51-63). Dordrecht: Springer

Harrison, A. G., \& Coll, R. K. (2008). Using analogies in middle and secondary science classrooms arrison A. G. \& Treagust. D. F. (1993). Teaching with anagies: A case study in grade 10 optics.

Journal of Research in Science Teaching, 30, 1291-1307.

states of matter are like students at school Australian Science Teachers Journal, 40, 20-23.

Harrison, A. G., \& Treagust, D. F. (1994b). A systematic approach for teaching with analogies: Homeostasis is like a student walking up the down escalator. The Science Teacher, 61, 40-43.

Harrison, A. G., \& Treagust, D. F. (2006). Teaching and learning with analogies: Friend or Foe? In P. J. Aubusson, A. G Harrison, \& S. M. Ritchie (Eds.), Metaphor and analogy in science education (pp. 11-24). Dordrecht, The Netherlands: Springer.

Harrison, A. G., \& de Jong, O. (2005). Using multiple analogies: Case study of a chemistry teacher's preparations, presentations and reflections. In K. Boersma, M. Goedhart, O. de Jong, \& H. Eijkelho (Eds.), Research and quality of science education (pp. 353-364). Dordrecht: Springer.

Harrison, A. G., \& Treagust, D. F. (2000). Learning about atoms, molecules and chemical bonds: A case-study of multiple model use in grade-11 chemistry. Science Education, 84, 352-381.

Ritchie, S. M., \& Russell, B. (1991). The construction and use of a metaphor for science teaching Research in Science Education, 21, 281-28.

Ritchie, S. M. (1994). Metaphor as a tool for constructivist science teaching. International Journal of Science Education, 16, 293-303.

作hie, S. M., Bellocchi, A., Poltt, H., \& Wearmouth, M. (2006). Metaphor and analogy in transition. In P. J. Aubusson, A. G. Harrison, \& S. M. Ritchie (Eds.), Metaphor and analogy in science

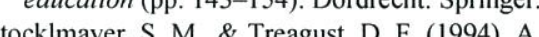

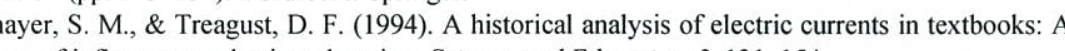
Science and Education, 3, 131-154.

Thiele, R. B., \& Treagust, D. F. (1993). Analogies in high school chemistry. Chemeda: Australian Journal of Chemical Education, 37, 19-25.

Thiele, R. B., \& Treagust, D. F. (1994). The nature and extent of analogies in secondary chemistry textbooks. Instructional Science, 22, 61-74.

Thiele, R. B., \& Treagust, D. F. (1995). Analogies in chemistry textbooks. International Journal of Science Education, 17, 783-795.

Thiele, R. B., \& Treagust, D. F. (1994). An interpretive examination of high school chemistry teachers' analogical explanations. Journal of Research in Science Teaching, 31, 227-242.

Thiele, R. B., Venville, G. J., \& Treagust, D. F. (1995). A comparative analysis in secondary biology an chemistry textbooks used in Australian schools. Research in Science Education, 25, 221-230.

Thomas, G. P. (2006). Metaphor, students conceptions of learning and teaching, and metacognition. In P. J. Aubusson, A. G. Harrison, \& S. M. Ritchie (Eds.), Metaphor and analogy in science education (pp. 105-117), Dordrecht: Springer.

Thomas, G. P., \& McRobbie, C. J. (1999a). The potential of metaphor for investigating and reforming teachers' and students' classroom practices. Education Practice and Theory, 21, 87-102.

Thomas, G. P., \& McRobbie, C. J. (1999b). Using metaphors to probe students' conceptions of learning. International Journal of Science Education, 21, 667-685

(201). Using a metaphor for learning to improve students

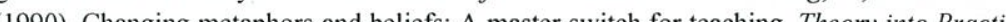
Tobin, K. (1993).

Education, 15, 241-254.

Edication, 15, 241-254. with higher-level cognitive learning. London: Falmer. 
Tobin, K., \& Tippins, D. (1996). Metaphors as seeds for conceptual change and the improvement of science teaching. Science Education, 80, 711-730.

Treagust, D. F. (2001). Using analogies in science teaching to engender students' interests, motivation and understanding. In M. A. Clements, H. H. Tairab, \& Ky Wong (Eds.), Energising science, mathematics and technical education for all (pp. 10-26). Gadong, Brunei: Univesiti Brune Darussalam

Treagust, D. F., \& Harrison, A. G. (2000b). In search of explanatory frameworks: An analysis of Richard Feynman's lecture "Atoms in motion". International Journal of Science Education, 22 $1157-1170$.

reagust, D. F., Duit, R. Joslin, P., \& Lindauer, I. (1992). Science teachers' use of analogies: Observations from classroom practice. International Journal of Science Education, 14, 413-422.

reagust, D. F., Harrison, A. G., \& Venville, G (1998). Teaching science effectively with analogies: An approach

Treagust, D. F., Harrison, A. G., Venville, G. J., \& Dagher, Z. (1996). Using an analogical teaching approach to engender conceptual change. International Journal of Science Education, 18, 213-1229. Treagust, D. F., Chittleborough, G., \& Mamiala, T. L. (2004). Students' understanding of the descriptive and predictive nature of teaching models in organic chemistry. Research in Science Education, 34, 1-20.

Treagust, D. F., Chittleborough, G., \& Mamiala, T. L. (2002). Students' understanding of the role of scientific models in learning science. International Journal of Science Education, 24, 357-368. reagust, D. F., \& Harrison, A. G. (2000). In search of explanatory frameworks: An analysis of Richard Feynman's lecture, "Atoms in motion". International Journal of Science Education, 22, 1157-1170. Venville, G. J., \& Treagust, D. F. (1998). Exploring conceptual change in genetics using a multidimensional interpretive framework. Journal of Research in Science Teaching, 35, 1031-1055. enville, G. J., \& Treagust, D. F. (1996). The role of analogies in promoting conceptual change in biology. Instructional Science, 24, 295-320.

F. (1994). Training students in the use of analogies to enhance understanding in science. Australian Science Teachers Journal, 40, 60-66.

Peter Aubusson

Faculty of Education

University of Technology Sydney

David Treagust

Science Mathematics Education Centre

Curtin University of Technology

Allan Harrision

Faculty of Education

Central Queensland University
BEV FRANCE AND MAVIS HAIGH

\section{THE PEDAGOGY OF PRACTICAL WORK} IN SCIENCE

In general, practical work in science education can be characterised by its activity and location. There is a view that practical work involves students "doing science" in laboratories although some areas of science education have traditionally had a significant involvement in out-of-classroom field-work, for example ecology and astronomy. As a result, for most of the $20^{\text {th }}$ Century the pedagogy of science education was focussed on how students could be organised in laboratories when "doing science". It was only when teachers were challenged not only by learning "doing science". It was only when teachers were challenged not only by learning theory, but also by classroom-based research that asked students about the purpose its promise.

Any chapter reviewing the pedagogy of practical work in school science needs first to consider its purpose and nature and then how this has changed over time. The place of practical work in school science is so taken for granted that explicit justifications are not generally required of curriculum documents and teaching materials. Australasian school science curricula have indicated, either directly or by implication, many purposes for practical work. These curricula have stated their reasons for including practical work as: developing conceptual understanding (declarative and procedural); developing skills; and developing improved attitudes towards science. It has also been argued that practical work may offer teachers the opportunity to induct learners into science so that they may share in the "wonder and excitement which have made the development of science such a great huma and cultural achievement" (Fensham, 1990, p. 300). In addition, practical work is sometimes presented as a means of helping students achieve generic educational outcomes such as logical thinking and problem solving.

Historically, the nature and purpose of practical work has changed. Research about practical work in Australasia has been scant. It was not until the 1970s that research became a major feature of science education in Australasia with the first ASERA conference in 1971 indicating its formal genesis (Northfield, 1990). Therefore to introduce this historical overview we have drawn from Northern Hemisphere sources.

As formal teaching in science developed in Britain and its colonies during the latter part of the nineteenth century, practical work became an important part of the school science curriculum (Lock, 1988). In the early decades of the $20^{\text {th }}$ Century the focus of practical work was influenced by Armstrong's heuristic approach an students were expected to discover things for themselves and solve problems. 